\title{
Determination of Personality Dimensions as per Sex and Area of Residence of College Students of Manipur
}

\author{
Dr. Subhaarati Oinam \\ Assistant ProfessorDepartment of EducationN. G. College
}

\begin{abstract}
This paper attempts to find out the relationship between sex and area of residence with respect to the two dimensions of personality (neuroticism and extraversion) of the college students in Manipur. Data were collected from a sample of 534 Meitei students in the age group 18-24, studying in both general and professional government colleges in the four (4) valley districts of Manipur. Data were statistically analysed using Chisquare test and percentage. Results indicated that significant relationship has been found between sex and area of residence with respect to A(average) category of both neuroticism and extraversion dimensions, while sex and area of residence are independent with respect to D (deviated), and HD (highly deviated) categories of both neuroticism and extraversion dimensions.
\end{abstract}

Key Words: Personality, Neuroticism, Extraversion.

\section{INTRODUCTION}

Personality is a person's enduring set of habits of thinking, feeling and acting. It is the "style" we carry through time (Schafer, 2004). The achievement in our life, career, family life, and our state of remaining healthy can be influenced by our personality and the personalities of people with whom we interact. In our day to day life, there are people who are affable, pleasant, nice to be around, and easy to get along with. They can be described as having a terrific personality and which we might want to select them as a friend, roommate, or colleague at work. Also, there are people who are aloof, hostile, aggressive, unfriendly, unpleasant, or difficult to get along with. Such people can be described as having a terrible personality and which we would not want to hire them or want to associate with them, and they may be similarly shunned, rejected, and isolated by others (Schultz and Schultz, 2007).

According to Gordon Allport, "Personality is the dynamic organisation within the individual of those psychophysical systems that determine his unique adjustments to his environment". Here, according to Allport, dynamic organisation means that although personality is constantly changing and growing, the growth is organised, not random. Psychophysical means that personality is composed of mind and body functioning together as a unit; personality is neither all mental nor all biological. Determine means that personality is made up of determining tendencies that play an active role in the individual's behaviour (Hall, Lindzey, and Campbell, 1998, p. 274).

\section{EYSENCK'S PERSONALITY TYPES:}

Different personality theories had developed over time and personality trait theory is also one, and is now enjoying a privileged status among personality researchers and an increasingly prominent role in studies done in social, developmental, cultural, and clinical psychology (Matthews et al., 2003) (cited in McAdams, and Pals, 2006). H. J. Eysenck is one of the trait theorists. According to him, personality is composed of traits, or factors, derived by the factor-analytic method. (Schultz and Schultz, 2007). Eysenck's type theory is based on three personality dimensions: extraversion-introversion, neuroticism-stability, and psychoticism (Roth, 1990).

The trait clusters that Eysenck associates with neuroticism, extraversion and introversion are shown in Figure 1(a), (b) and (c) respectively. 

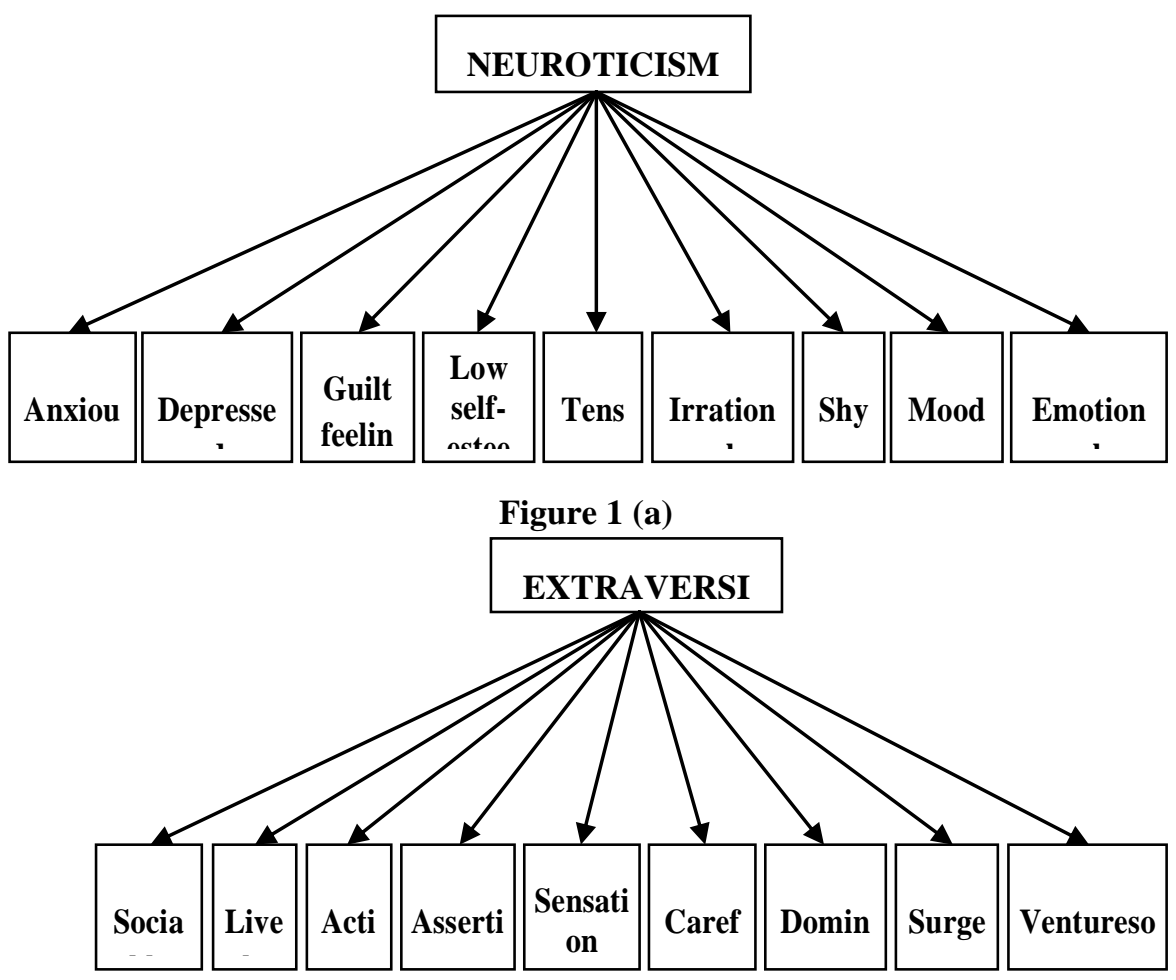

Figure 1 (b)

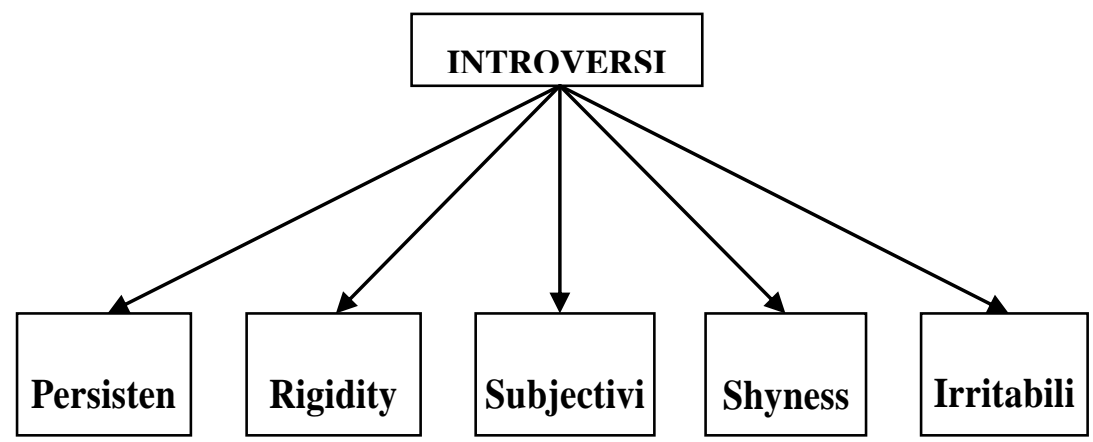

Figure $1(\mathbf{c})$

Figure 1: Traits making up the type concept of (a) neuroticism, (b) extraversion. Source: Hall, Lindzey, and Campbell, 2002, p. 363. (c) introversion. Source: Roth, 1990, p. 386.

It is evident that the cluster of extraversion traits shown in Fig. 1(b) is quite different from the cluster of neuroticism traits shown in Fig. 1(a). In Eysenck's theory, the underlying biological cause of extraversion is quite unrelated to the biological cause of neuroticism. He believes that a person's position on the personality dimension extraversion-introversion is caused by the level of arousal in the brain, and that their position on the neuroticism-stability dimension is caused by the stability or lack of stability (i.e., the liability) of the automatic nervous system (Roth, 1990).A particular contribution of Eysenck is that he has found a basis for these dimensions in modern scientific knowledge about the neurophysiology of the nervous system. Eysenck's MPI (the Maudsley Personality Inventory) and the EPI (the Eysenck Personality Inventory) are in continuous use today and vast amount of research has been conducted on a wide range of individual differences in psychology by using these questionnaires (Roth, 1990).

\section{OBJECTIVE OF THE STUDY}

(i) To find out the relationship between sex and area of residence with respect to the two dimensions of personality (neuroticism and extraversion) of the college students. 


\section{HYPOTHESIS OF THE STUDY}

(i) There exists no significant relationship between the sex and area of residence with respect to the two dimensions of personality.

\section{METHOD OF THE STUDY}

The survey approach under the descriptive research method was adopted in the present investigation.

POPULATION: There are twenty-seven (27) government colleges in the four (4) valley districts of Manipur as per 'List of Affiliated Government Colleges' issued by the College Development Council (CDC), Manipur University. Out of this, eighteen (18) colleges are providing general education and nine (9) colleges are providing professional education. Altogether, 534 Meitei students studying in the 27 colleges formed the universe of the study.

\section{SAMPLE}

Incidental Sampling was adopted in the selection of the sample to be studied.

\section{TOOLS USED:}

In this study, Maudsley Personality Inventory (MPI) developed by H. J. Eysenck was used to give a rough-andready measure of two important personality dimensions: Neuroticism or emotionality, and Extraversion. For both the dimensions of personality, students were placed according to their scores under A (average), D (deviated), and HD (highly deviated) categories. They are explained below:

- HD (highly deviated): According to Eysenck's type theory, an individual can be placed in relation to the two dimensions- extraversion-introversion and neuroticism-stability depending on their scores on these two dimensions. People with very high or very low scores are placed at the extremes (Roth, 1990). In this study, whose standard score is above 70 or below 30 is placed in the 'highly deviated (HD)' category and they indicate a very considerable deviation from the average (Eysenck, 1993).

- D (deviated): Whose standard score is in the range 30-39, 61-70 is 'equal to deviated (D)' and they need attention (Eysenck, 1993).

- A (average): Whose standard score is in the range 40-60 is designated 'equal to the average (A)' (Eysenck, 1993). In Eysenck's type theory, most average people fall somewhere in the middle, without extreme scores on either dimensions (Roth, 1990).

\section{DATA ANALYSIS}

The data were analysed with the help of SPSS and computed accordingly. Percentage and Chi-square test were used to analyse and interpret the data.

\section{RESULTS AND DISCUSSION}

1) Sex and area of residence with respect to Personality Dimensions

a) Relationship between sex and area of residence with respect to neuroticism dimension

Table 1(a)

Relationship between sex and area of residence with respect to neuroticism dimension

\begin{tabular}{|c|c|c|c|c|c|c|}
\hline \multirow{2}{*}{ Neuroticism } & \multirow{2}{*}{$\begin{array}{l}\text { Area of } \\
\text { residence }\end{array}$} & \multicolumn{2}{|c|}{ Sex of the respondent } & \multirow[t]{2}{*}{ Total } & \multirow{2}{*}{$\chi^{2}$} & \multirow{2}{*}{ p-value } \\
\hline & & Male & Female & & & \\
\hline \multirow{3}{*}{ A } & Rural & $120(53.1)$ & $106(46.9)$ & $226(100.0)$ & \multirow{3}{*}{7.945} & \multirow{3}{*}{0.005} \\
\hline & Urban & $54(38)$ & $88(62)$ & $142(100.0)$ & & \\
\hline & Total & $174(47.3)$ & $194(52.7)$ & $368(100.0)$ & & \\
\hline \multirow{3}{*}{$\mathrm{D}$} & Rural & $28(37.8)$ & $46(62.2)$ & $74(100.0)$ & \multirow{3}{*}{2.009} & \multirow{3}{*}{0.156} \\
\hline & Urban & $14(25.9)$ & $40(74.1)$ & $54(100.0)$ & & \\
\hline & Total & $42(32.8)$ & $86(67.2)$ & $128(100.0)$ & & \\
\hline \multirow{3}{*}{ HD } & Rural & $18(64.3)$ & $10(35.7)$ & $28(100.0)$ & \multirow{3}{*}{0.058} & \multirow{3}{*}{0.809} \\
\hline & Urban & $6(60)$ & $4(40)$ & $10(100.0)$ & & \\
\hline & Total & $24(63.2)$ & $14(36.8)$ & $38(100.0)$ & & \\
\hline
\end{tabular}

(Figures in parentheses indicate percentage) $\mathrm{N}=534$

Table 1(a) reflects that female respondent's percentage was more than male respondents in categories $\mathrm{A}$ and D. It also indicates that in the case of A and D categories, the rate of males from rural areas were higher 
than urban males while it was the reverse in the case of females. But in the case of HD category, male respondents were higher than female respondents. More rural males belonged to this category than urban males, while more urban females belonged to this category than rural females. In all the three categories, urban females stood higher than rural females while it was the opposite in the case of males.

About the result on the relation between sex and area of residence with respect to A category it was found that there was significant relationship as $\chi^{2}=7.945$ with p-value 0.005 which is less than 0.05 while sex and area of residence are independent while determining the D, and HD categories of neuroticism dimension of personality of students as $\chi^{2}=2.009$ with p-value 0.156 which is greater than 0.05 for $\mathrm{D}$ category and for HD category $\chi^{2}=0.058$ with $\mathrm{p}$-value 0.809 which is greater than 0.05 . Khalane, and Borse (2010) had revealed that urban or rural as well as male or female did not affect his/her personality.

b) Relationship between sex and area of residence with respect to extraversion

Table 1(b)Relationship between sex and area of residence with respect to extraversion

\begin{tabular}{|c|c|c|c|c|c|c|}
\hline \multirow[t]{2}{*}{ Extraversion } & \multirow{2}{*}{$\begin{array}{c}\text { Area of } \\
\text { residence }\end{array}$} & \multicolumn{2}{|c|}{ Sex of the respondent } & \multirow{2}{*}{ Total } & \multirow{2}{*}{$\chi^{2}$} & \multirow{2}{*}{ p-value } \\
\hline & & Male & Female & & & \\
\hline \multirow{3}{*}{ A } & Rural & $120(51.3)$ & $114(48.7)$ & $234(100.0)$ & \multirow{3}{*}{11.936} & \multirow{3}{*}{0.001} \\
\hline & Urban & $50(33.3)$ & $100(66.7)$ & $150(100.0)$ & & \\
\hline & Total & $170(44.3)$ & $214(55.7)$ & $384(100.0)$ & & \\
\hline \multirow{3}{*}{$\mathrm{D}$} & Rural & $28(40)$ & $42(60)$ & $70(100.0)$ & \multirow{3}{*}{0.103} & \multirow{3}{*}{0.748} \\
\hline & Urban & $14(36.8)$ & $24(63.2)$ & $38(100.0)$ & & \\
\hline & Total & $42(38.9)$ & $66(61.1)$ & $108(100.0)$ & & \\
\hline \multirow{3}{*}{ HD } & Rural & $18(75)$ & $6(25)$ & $24(100.0)$ & \multirow{3}{*}{1.750} & \multirow{3}{*}{0.186} \\
\hline & Urban & $10(55.6)$ & $8(44.4)$ & $18(100.0)$ & & \\
\hline & Total & $28(66.7)$ & $14(33.3)$ & $42(100.0)$ & & \\
\hline
\end{tabular}

(Figures in parentheses indicate percentage) $\mathrm{N}=534$

An examination of Table 1(b) indicates that female respondent's percentage was more than male respondents in A category. It can also be noted that in this category, males from rural areas were higher than urban males, while urban females stood higher than the rural females. In the case of D category also, higher percentage of female was found as compared to males. $40 \%$ males were from rural and $36.8 \%$ from urban which indicates that higher percentage of rural male belonged to D category as compared to urban males while there was higher percentage of urban females than rural females. But in the case of HD category, male respondents were higher than female respondents. More rural males belonged to this category than urban males, while it was the reverse in the case of females.

It was found that the relation between sex and area of residence with respect to A category was significant as $\chi^{2}=11.936$, with p-value 0.001 which is less than 0.05 . In the case of $\mathrm{D}$, and HD categories of extraversion dimension of students, sex and area of residence are found to be independent as $\chi^{2}=0.103$, with p-value 0.748 which is greater than 0.05 for D category, and $\chi^{2}=1.750$, with $\mathrm{p}$-value 0.186 which is greater than 0.05 for HD category.

\section{MAIN FINDINGS}

From the above results and discussion, the findings of the study are revealed as follows:

Female respondent's percentage was more than male respondents in A and D categories of both extraversion and neuroticism dimensions of personality. The percentage of males from rural areas were higher than urban males, while urban females stood higher than the rural females in A and D categories of both extraversion and neuroticism dimensions. In the case of HD category of both the dimensions, male respondents were higher than female respondents and also more rural males belonged to this category than urban males, while it was the reverse in the case of females. The relationship between sex and area of residence has been found with respect to A category of both neuroticism and extraversion dimensions, while sex and area of residence are independent with respect to D, and HD categories of both neuroticism and extraversion dimensions. 


\section{CONCLUSION}

It can thus be concluded that there is significant relationship between sex and area of residence with respect to A category of both neuroticism and extraversion dimensions, while there is no relationship between sex and area of residence with respect to $\mathrm{D}$, and $\mathrm{HD}$ categories of both neuroticism and extraversion dimensions.

\section{REFERENCES}

[1] College Development Council. List of Affiliated Government Colleges; Manipur University: Canchipur. [2] Eysenck, H. J. Manual for Maudsley Personality Inventory. Author, 1993, p. 14.

[3] Hall, C. S., Lindzey, G., and Campbell, J. B. Theories of Personality. $4^{\text {th }}$ Edition; John Wiley and Sons: Singapore, 2002, p. 274.

[4] Khalane, S. H. and Borse, A. S. (2010). The personality of child and the parental attitude of father and mother in single and sibling child family. Asian Journal of Psychology and Education, Vol. 43, No. 34, pp. 5-11.

[5] McAdams, D. P., and Pals, J. L. A New Big Five. American Psychologist. Vol. 61. No.3, 2006, p. 204217.

[6] Roth, I. (1990). (Ed.). Introduction to Psychology. Vol. 1. London: Lawrence Erlbaum Associates in association with Open University, p. 385-386.

[7] Schafer, W. (2004). Stress Management for Wellness. $4^{\text {th }}$ Edition. Singapore: Thomson Asia.

[8] Schultz, D. P., and Schultz, S. E. Theories of Personality. $8^{\text {th }}$ Edition; Rahul Print O Pack: Delhi, 2007, p.289. 